$6-9-2021$

\title{
Reducing HIV risk for adolescent girls and young women and their male partners: Learnings from the DREAMS Partnership
}

\author{
Julie Pulerwitz \\ Population Council \\ Ann Gottert \\ Population Council \\ Jerry Okal \\ Population Council \\ Sanyukta Mathur \\ Population Council
}

Follow this and additional works at: https://knowledgecommons.popcouncil.org/departments_sbsr-hiv How does access to this work benefit you? Let us know!

\section{Recommended Citation}

Pulerwitz, Julie, Ann Gottert, Jerry Okoth Okal, and Sanyukta Mathur. 2021. "Reducing HIV risk for adolescent girls and young women and their male partners: Learnings from the DREAMS Partnership," presentation to the Bill and Melinda Gates Foundation, 9 June. 


\section{POPULATION COUNCIL}

Ideas. Evidence. Impact.

\section{REDUCING HIV RISK FOR} ADOLESCENT GIRLS AND YOUNG WOMEN \& THEIR MALE PARTNERS

Learnings from the DREAMS Partnership

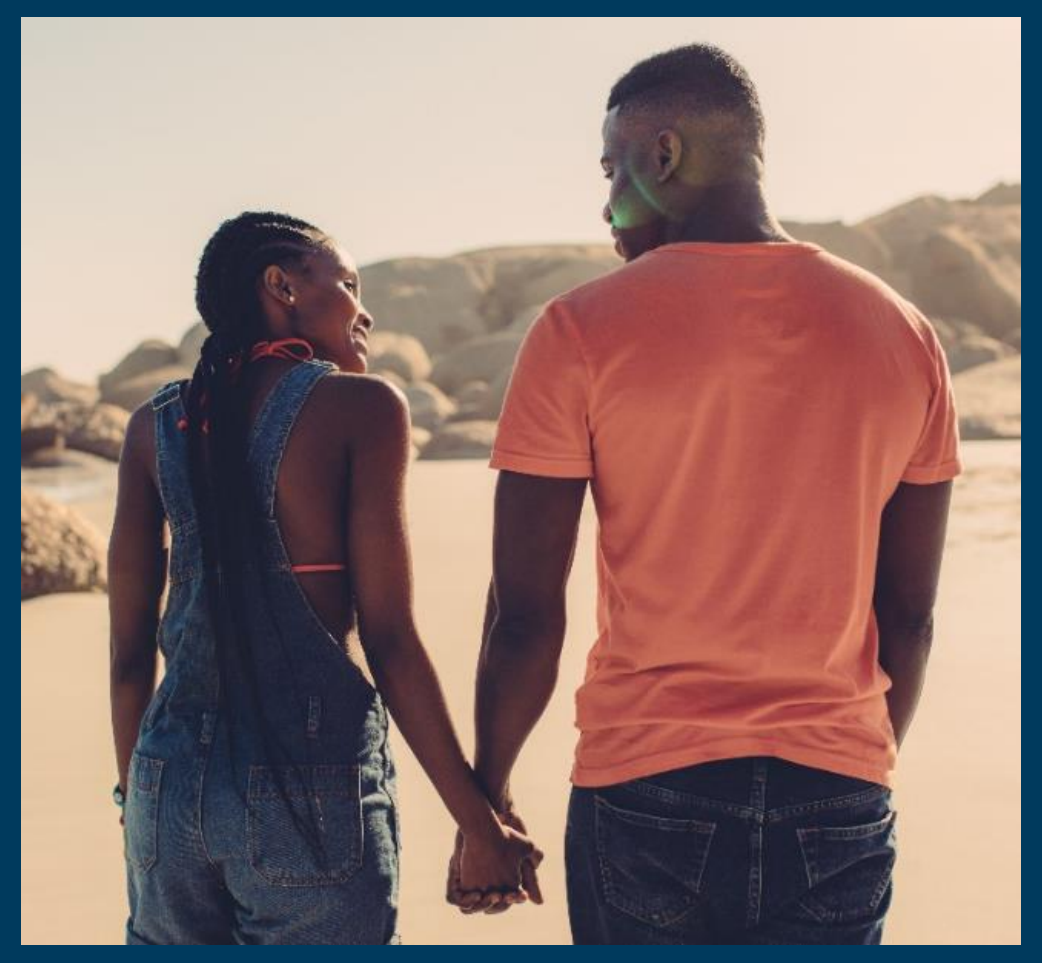

9 June 2021 


\section{Today's presenters}

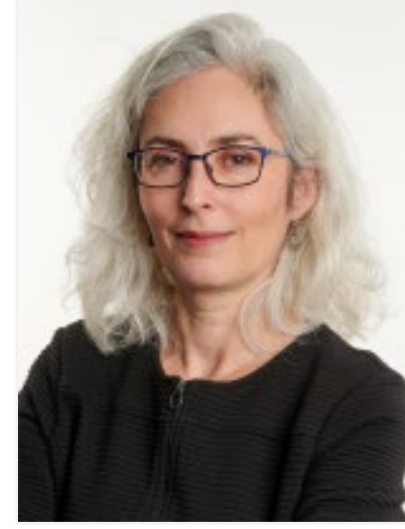

Julie Pulerwitz, ScM, ScD

Director, HIV and AIDS

Program

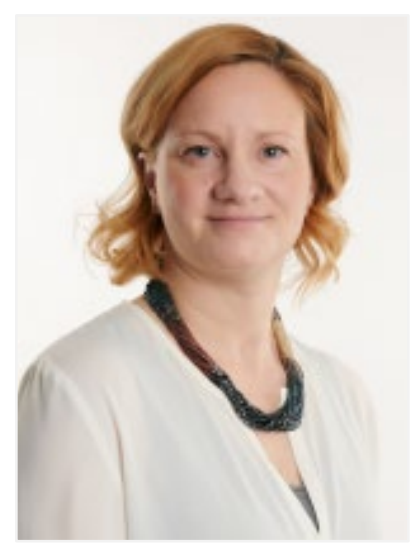

Ann Gottert, PhD, MPH

Research Associate

Jerry Okal, PhD, MPH

Research Associate

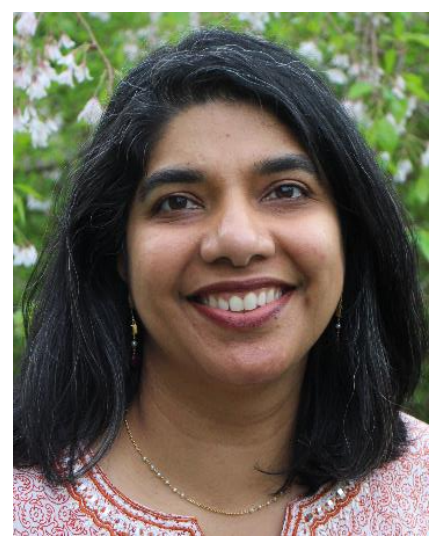

Sanyukta Mathur, PhD, MHS

Project Director,

DREAMS Implementation

Science Research Portfolio 


\section{DREAMS Implementation Science (IS) Research}

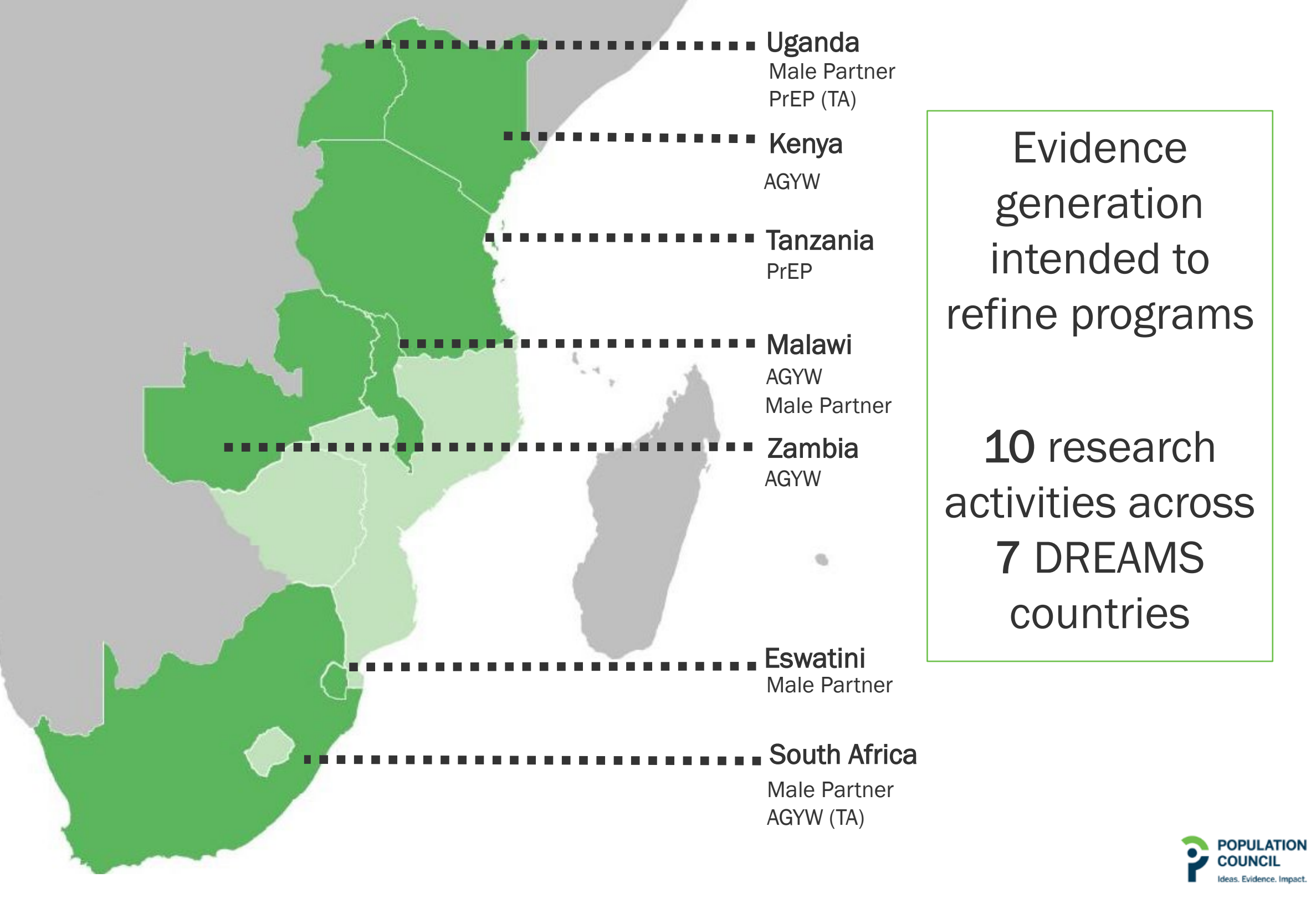




\section{Iterative, consensus-building process for IS agenda}

Initial PEPFAR-hosted meeting Johannesburg (Jan 2015)

Review IS Qs posed by PEPFAR country teams \& literature review
Follow on discussions with individual country teams and PEPFAR/HQ

Priority IS themes identified based on countries' interest, global knowledge gaps, \& mapped onto DREAMS core package $\downarrow$

Study countries selected through individual discussions with country teams and PEPFAR/HQ and match with 3 key topics (2015)

Study concept notes developed for each proposed study (2015)

Study sites and agency roles negotiated with DREAMS country teams $\&$ PEPFAR/HQ

Partnerships established with implementing partners at study sites (2016)

Study protocols developed/refined in consultation with stakeholders (2016-17) 


\section{Research approach}

2-phased study design

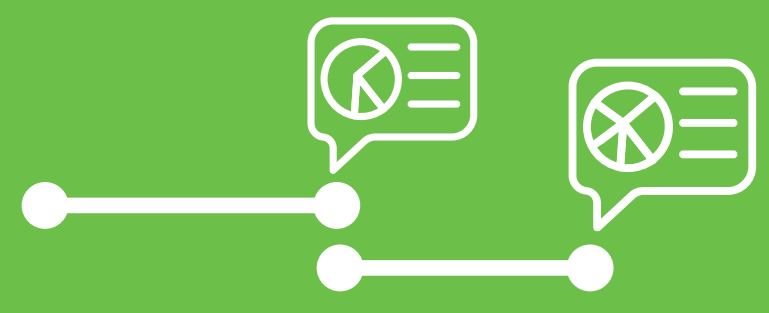

Multiple perspectives

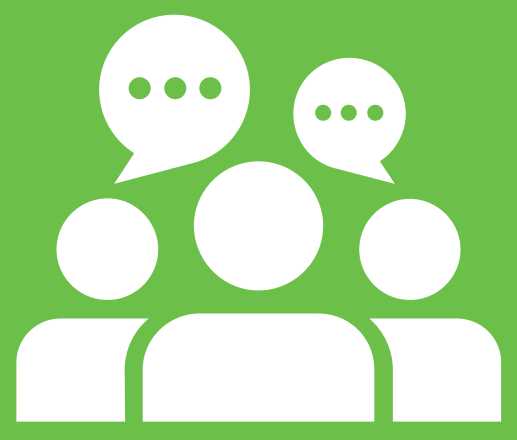

Mixed methods
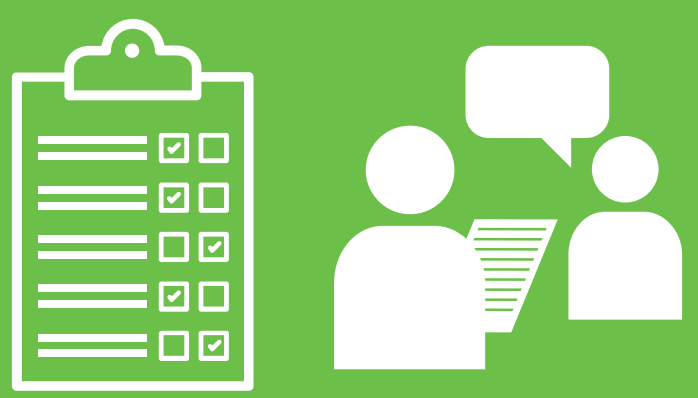

Engaging stakeholders

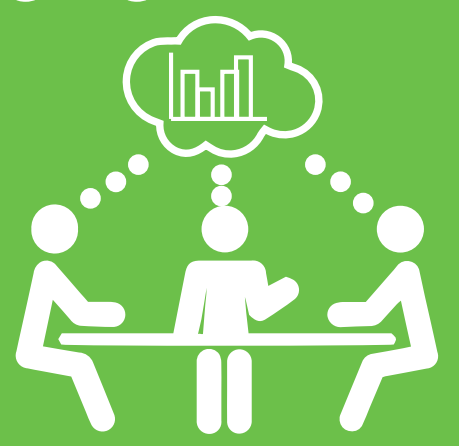




\section{The Core Package}

\section{DREAMS}

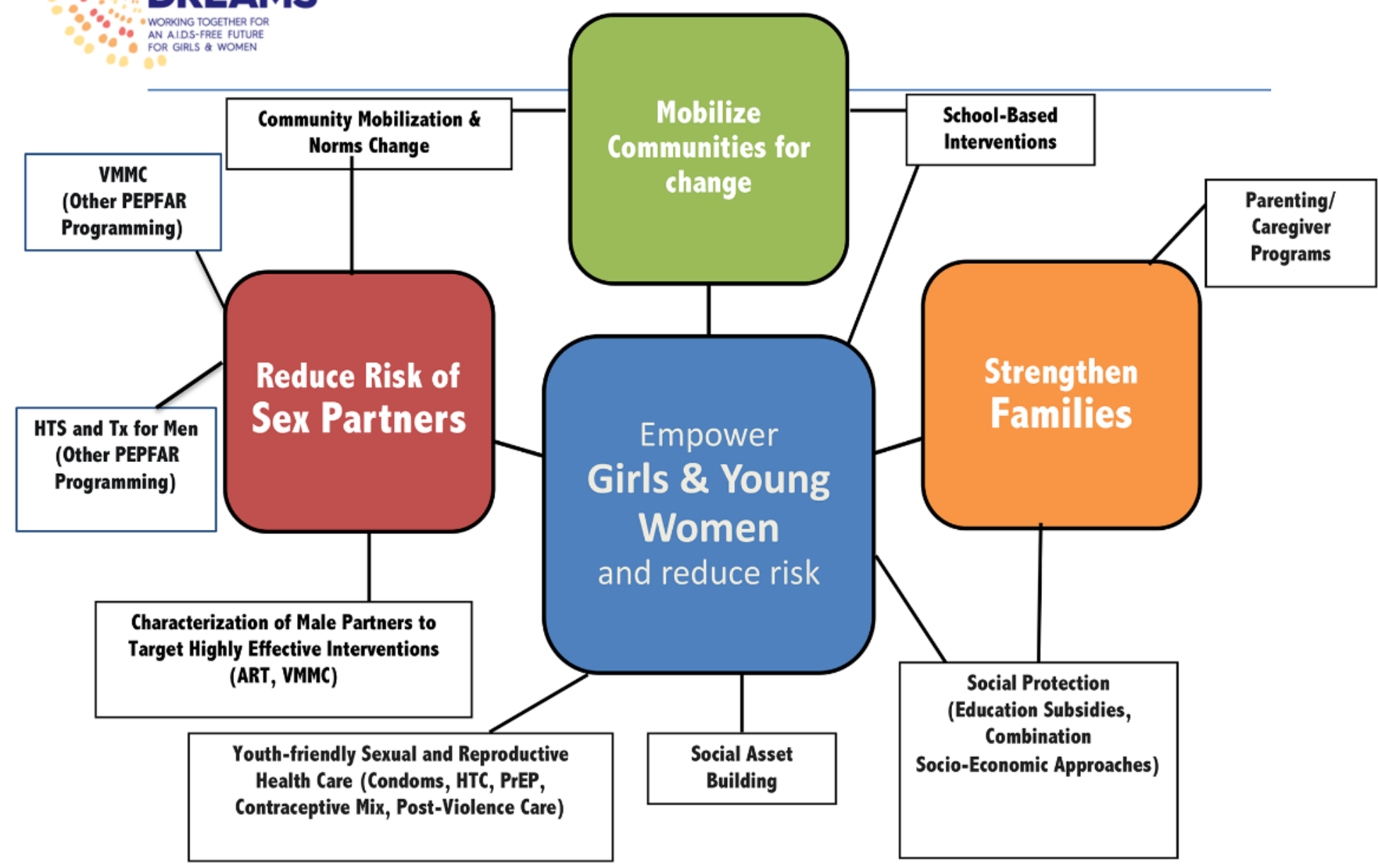

\section{Determined \\ Resilient \\ Empowered \\ Mentored \\ Safe}

Saul J, Bachman G, Allen S, Toiv NF, Cooney C, et al. (2018) The DREAMS core package of interventions: A comprehensive approach to preventing HIV among adolescent girls and young women. PLOS ONE 13(12): e0208167. doi: 10.1371/journal.pone.0208167 


\section{Range of methodological approaches}

\section{How can we better define HIV vulnerability/risk?}

- Employ Latent Class Analysis to understand WHO to reach, WHERE, and with WHAT programming

How effective is multi-sectoral community-based HIV prevention programming?

- Employ Classification and Regression Trees to assess which combinations of programs increase the likelihood of desired outcomes, and for whom

\section{How to successfully implement such a program?}

- Assess program Reach, Effectiveness, Adoption, Implementation, and Maintenance from participant and implementer perspectives

\section{What are facilitators/barriers to PrEP use for AGYW?}

- Assess end-user and provider preferences using mixed methods approaches 


\section{Study sites \& data}

\begin{tabular}{|c|c|c|c|c|c|c|c|}
\hline & Kenya & Tanzania & Zambia & Malawi & Eswatini & $\begin{array}{l}\text { South } \\
\text { Africa }\end{array}$ & Uganda \\
\hline 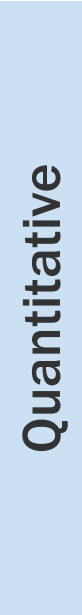 & $\begin{array}{l}\text { DREAMS/ } \\
\text { non-DREAMS } \\
\text { AGYW } \\
\mathrm{N}=1,778 \\
\text { Panel data } \\
\text { DREAMS } \\
\text { AGYW } \\
\mathrm{n}=740\end{array}$ & $\begin{array}{l}\text { Health } \\
\text { provider } \\
\text { survey } \\
n=361\end{array}$ & $\begin{array}{l}\text { DREAMS/ } \\
\text { non-DREAMS } \\
\text { AGYW } \\
\mathrm{N}=1,915 \\
\text { Panel data } \\
\text { DREAMS } \\
\text { AGYW } \\
\mathrm{n}=885\end{array}$ & $\begin{array}{l}\text { Round } 1 \\
\text { DREAMS } \\
\text { AGYW } \\
n=1,672 \\
\text { Panel data } \\
\text { DREAMS } \\
\text { AGYW } \\
n=1,257 \\
\text { Men/MP of } \\
\text { AGYW } n=612\end{array}$ & $\begin{array}{l}\text { Men in 'hot } \\
\text { spots' } \\
\text { Round } 1 \\
\text { (MEASURE } \\
\text { Evaluation) } \\
n=843 \\
\text { Round } 2 \\
n=1,180\end{array}$ & $\begin{array}{l}\begin{array}{l}\text { Men in } \\
\text { informal } \\
\text { settlements }\end{array} \\
\text { Round } 1 \\
n=962 \\
\text { Round } 2 \\
n=886\end{array}$ & \\
\hline 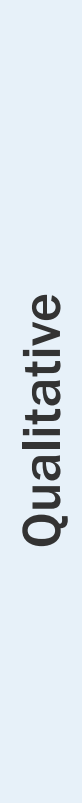 & $\begin{array}{l}\text { DREAMS } \\
\text { beneficiaries } \\
n=27 \text { IDIs } \\
\text { Program } \\
\text { staff } \\
n=27 \text { IDIs }\end{array}$ & $\begin{array}{l}\text { FSWs } \\
n=24 \text { IDIs } \\
\text { Unmarried } \\
\text { AGYW } \\
n=4 \text { FGDs } \\
\text { Policymakers } \\
n=21 \text { IDIs } \\
\text { Parents / } \\
\text { guardians } \\
n=4 \text { FGDs } \\
\text { MP of AGYW } \\
n=16 \text { IDIs }\end{array}$ & $\begin{array}{l}\text { DREAMS } \\
\text { beneficiaries } \\
n=44 \text { IDIs } \\
\text { Program } \\
\text { staff } \\
n=31 \text { IDls }\end{array}$ & $\begin{array}{l}\begin{array}{l}\text { DREAMS } \\
\text { beneficiaries } \\
n=36 \text { IDIs }\end{array} \\
\text { Program } \\
\text { staff } \\
n=35 \text { IDIs } \\
\text { Facilitators } \\
n=18 \text { FGDs } \\
\text { Men living } \\
\text { with HIV } \\
n=4 \text { FGDs \& } \\
16 \text { IDIs }\end{array}$ & $\begin{array}{l}\text { MP of AGYW } \\
n=66 \text { IDIs } \\
\text { Program } \\
\text { staff } \\
n=3 \text { FGDs }\end{array}$ & $\begin{array}{l}\text { MP of AGYW } \\
n=72 \text { IDIs } \\
\text { Program } \\
\text { staff } \\
n=3 \text { FGDs }\end{array}$ & $\begin{array}{l}\text { MP of AGYW } \\
n=126 \text { IDIs } \\
\text { Program } \\
\text { staff } \\
n=9 \text { FGDs }\end{array}$ \\
\hline
\end{tabular}




\section{Expanding the evidence base on HIV prevention}

10 peer-reviewed publications

(with 8 more under review)
14 theme or country focused research briefs
65 presentations for global stakeholders
47 presentations for country stakeholders 


\section{Upcoming contributions to global literature}

- Examples of themes:

- PrEP cascade for AGYW

- Differential unit costs of delivering AGYW programming

- Effects of layered programming for AGYW

- Men's common exposure to trauma and negative outcomes

- Future directions for engaging men in HIV prevention

- Financial agency, gender dynamics, and HIV risk

- Special issue in high-impact journal AIDS with papers from Population Council, PEPFAR, and London School of Hygiene and Tropical Medicine

- Supporting special issue in the journal Tropical Medicine and Infectious Disease focused on solutions for HIV prevention 


\section{Successful research uptake acknowledges different stakeholder perspectives}
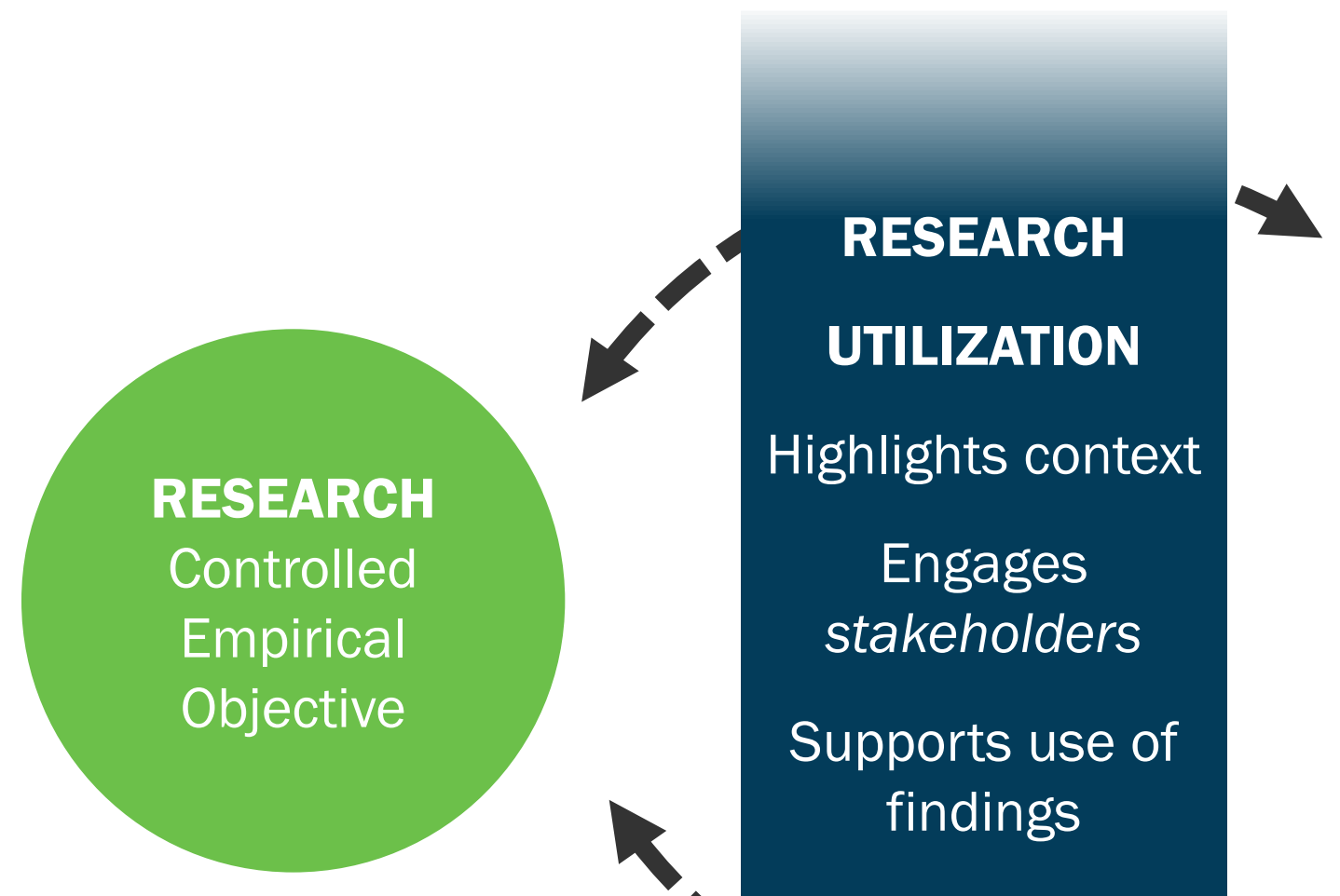

PROGRAM

Practical

Urgent

Action-

Oriented

Engages

stakeholders

Supports use of findings

Builds ownership

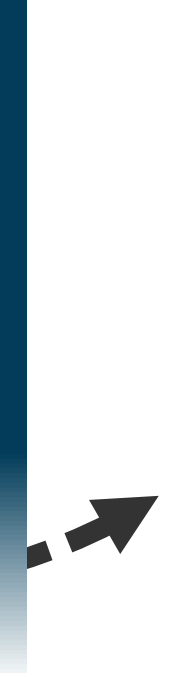

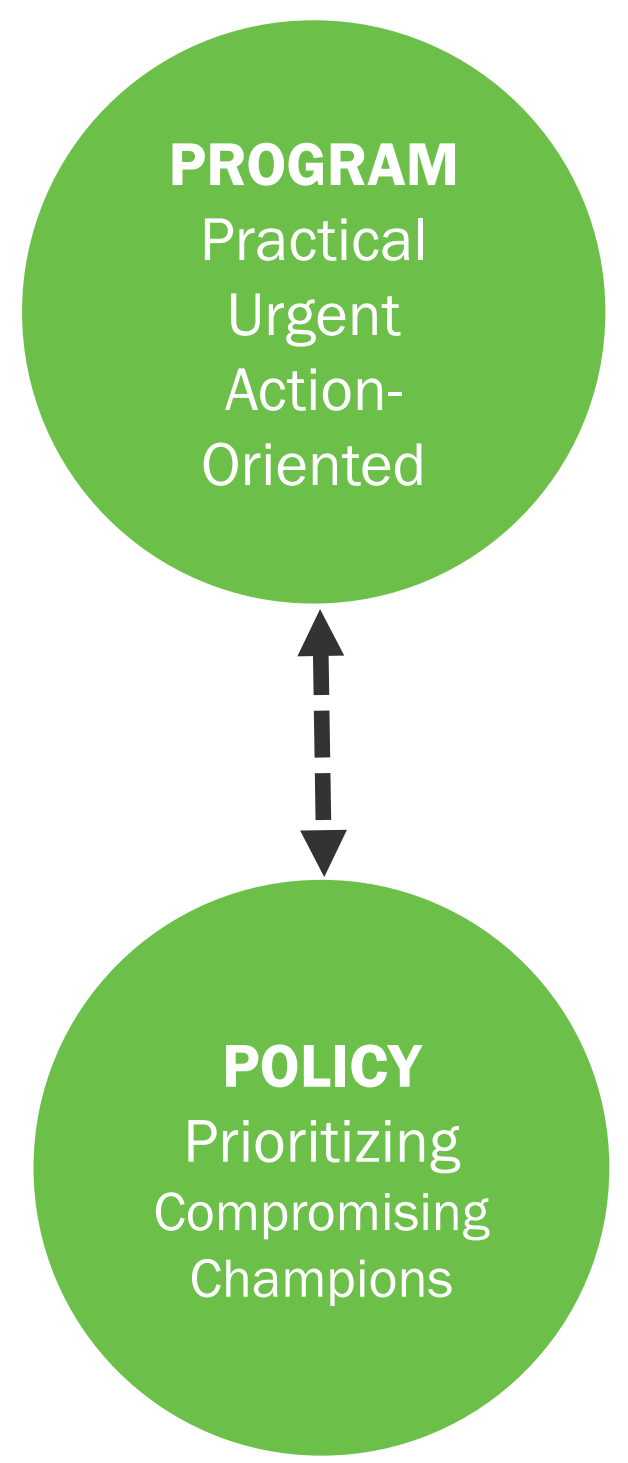




\section{How effective is the multi-sectoral}

community-based HIV prevention programming? 


\section{Need to sustain}

significant

improvements

in HIV

knowledge,

self-efficacy, \&

HIV testing
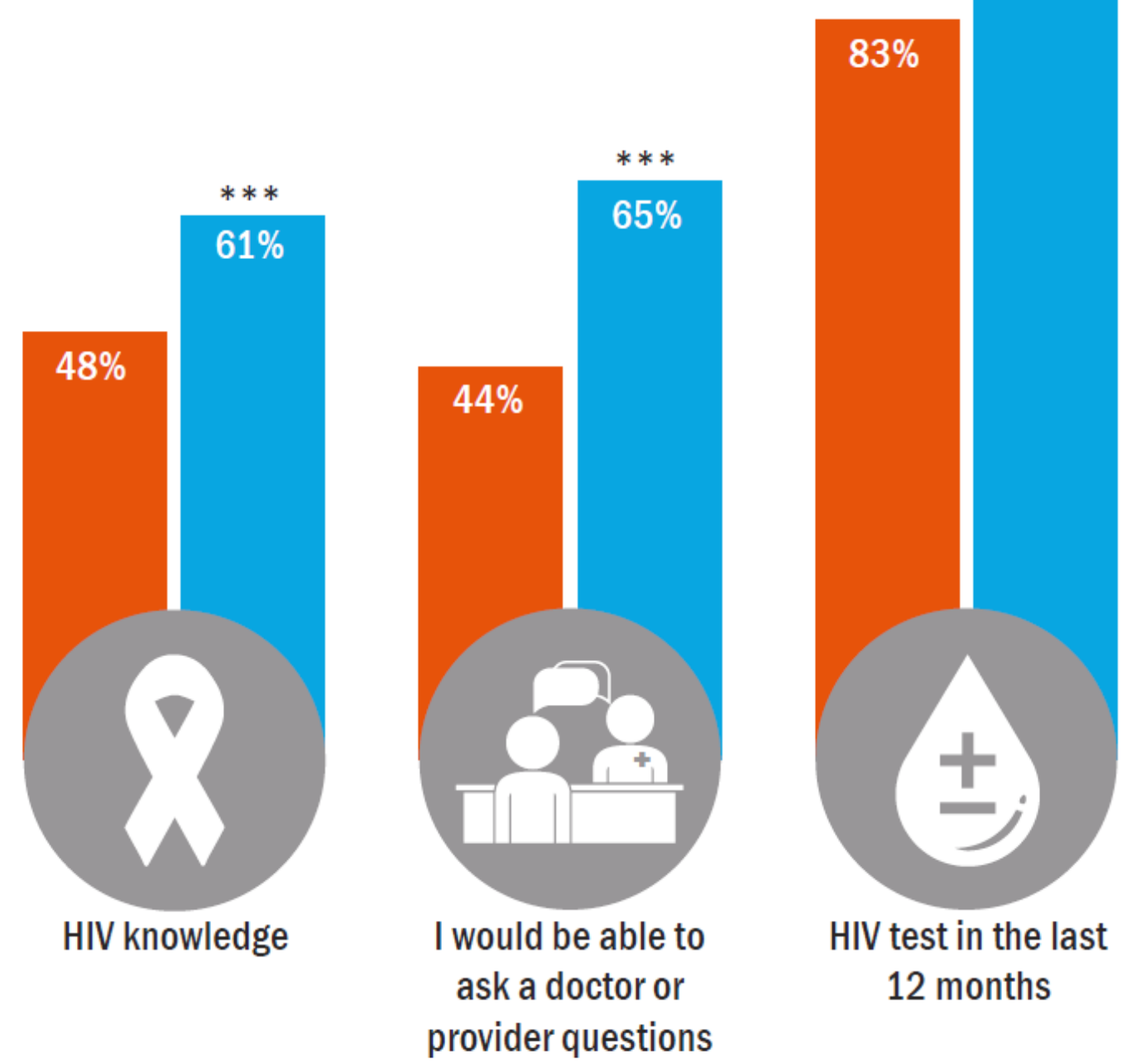

$* * * \mathrm{p}<0.001$

Note: similar results in Kenya and Zambia 
Need to sustain reductions in experience of sexual violence from partners and nonpartners over time

\begin{tabular}{|c|c|c|}
\hline \multirow{2}{*}{$\begin{array}{l}\text { Experience of violence in the past } 12 \\
\text { months }\end{array}$} & \multicolumn{2}{|c|}{$\begin{array}{c}\text { Kenya } \\
(n=736)\end{array}$} \\
\hline & $\begin{array}{c}\text { Round } 1 \\
\%\end{array}$ & $\begin{array}{c}\text { Round } 2 \\
\%\end{array}$ \\
\hline \multicolumn{3}{|l|}{ Among sexually active } \\
\hline Sexual violence from partners & 20 & $9^{* * *}$ \\
\hline \multicolumn{3}{|l|}{ Among all AGYW } \\
\hline Sexual violence from non-partners & 26 & $17^{* * *}$ \\
\hline
\end{tabular}

- Regressions confirm that AGYW are less likely to experience sexual violence from partners (Adj. IRR $0.43(0.31-0.59))$ and from non-partners $(0.65$ (0.53-0.81)) over time.

Note: similar results in Malawi \& Zambia 


\section{Need to redouble efforts on supporting HIV risk avoidance during key life transitions}

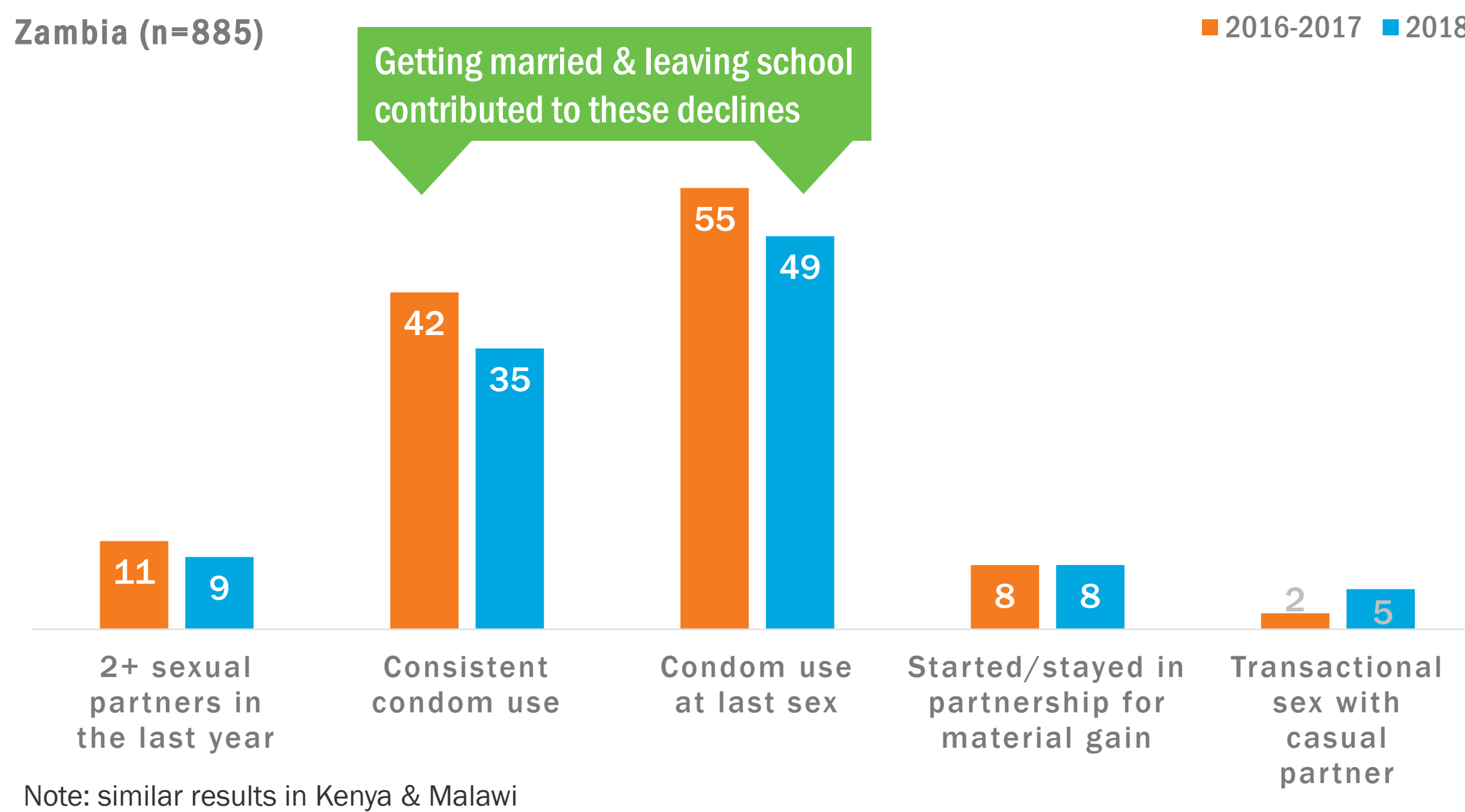

Note: similar results in Kenya \& Malawi 


\section{What pathways reduced likelihood of transactional sex?}

\author{
$15-19$ \\ years \\ $20-24$ \\ years
}
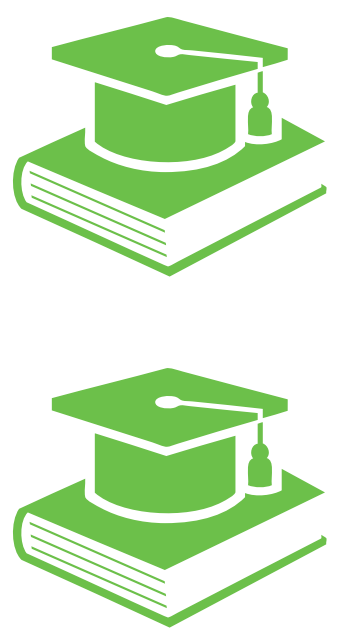

Schooling

support

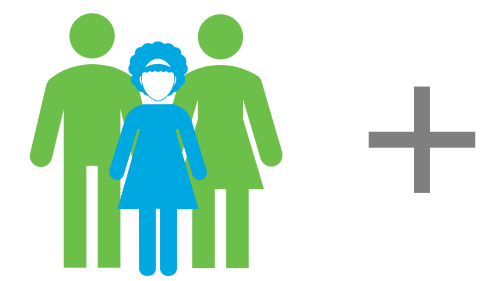

Parenting program

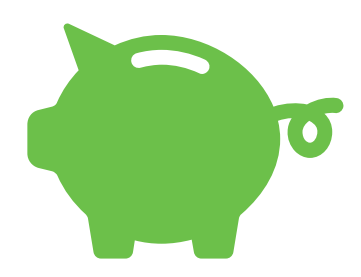

Youth fund

program

Study sites: Kenya, $(\mathrm{n}=736)$, CART analysis 


\section{Distinct subgroups of men found, who should be targeted differently with programming}

- Not just older high-risk men, younger men have high HIV risk profiles too.

- Risk profiles of older and younger men don't look the same.

- Distinguishing variables include type of employment, gender attitudes, alcohol use, number of partners, etc.

- Higher-risk profiles were less or no more likely to use HIV services than lower-risk profiles

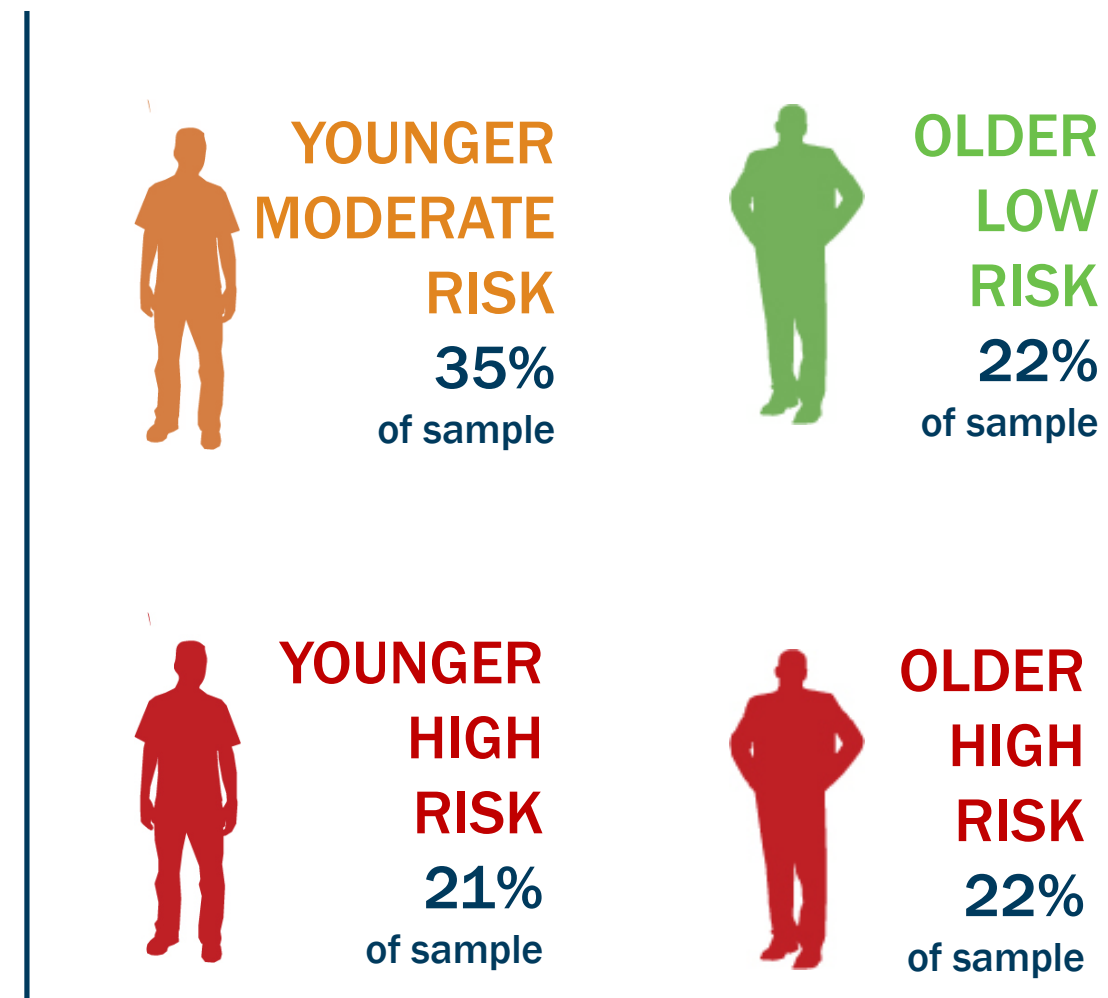




\section{Male partners of DREAMS AGYW described benefits}

- Learning about social/gender norms from partners, and own direct participation

- Commonly cited impacts included:

- Improved couple communication \& conflict resolution

- Reducing/eliminating side partners

- More impetus to link to HIV services

[We] now know how to communicate with each other... we no longer have arguments over simple things....

-Male partner, Mukono
The meeting taught me, as a person, to be safe, and practice self-control.... Have one partner [and] stop admiring other women....

-Male partner, Sembabule

Study site: Uganda; similar findings in Eswatini and South Africa 


\section{How do you successfully}

\section{implement a comprehensive HIV prevention program for AGYW?}




\section{Early engagement of stakeholders}

- $1^{\text {st }}$ study in Tanzania to assess feasibility \& acceptability of oral PrEP for young women outside of a clinical setting

- Engaged stakeholders to gather input into key questions before data collection

- Stakeholders engaged in data interpretation/study implications and provided insights on potential challenges \& strategies for PrEP roll-out in Tanzania

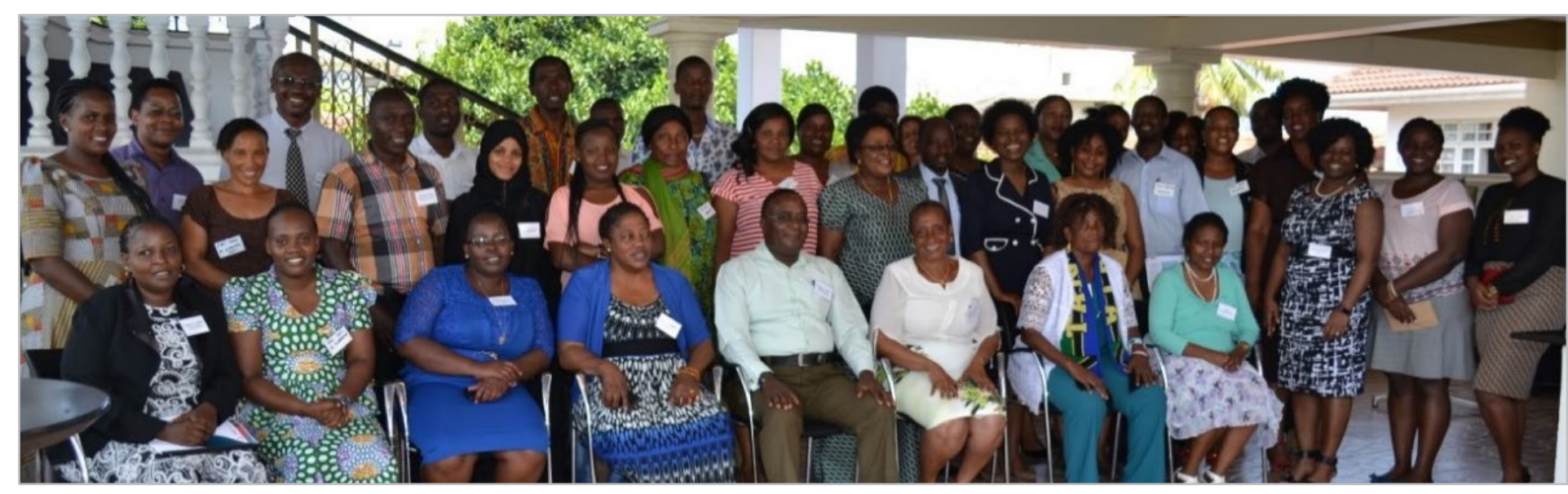




\section{Reaching the most-at-risk AGYW}

- Vulnerability was assessments included several phases (e.g., community mapping, OVC rosters) and a range of criteria (e.g., living next to a hotspot, victim of violence)

- Community leaders helped identify the most vulnerable girls
- Yet, early findings showed that DREAMS was still missing some AGYW

\begin{tabular}{lcc} 
KENYA & $\begin{array}{c}\text { DREAMS } \\
(\mathrm{n}=914) \\
\%\end{array}$ & $\begin{array}{c}\text { Non- } \\
\text { DREAMS } \\
(\mathrm{n}=864) \\
\%\end{array}$ \\
$\begin{array}{l}\text { Currently in } \\
\text { school }\end{array}$ & 58 & 27 \\
\hline
\end{tabular}

Note: similar results in Malawi \& Zambia 


\section{Even in HIV} prevalence contexts, differences in HIV vulnerability

\section{Multiple characteristics synergistically define high vulnerability}

$\begin{array}{ccc}\begin{array}{c}\text { Kenya } \\ (n=1,014)\end{array} & \text { Malawi } & \text { Zambia } \\ (n=1,652) & (n=846)\end{array}$

Higher HIV vulnerability

Moderate HH wealth

Lack of adult supervision

Sometimes/often hungry

No comprehensive knowledge of HIV

No comprehensive knowledge of condoms

Lower support for equitable gender norms

\section{$32 \% \quad 53 \% \quad 51 \%$}
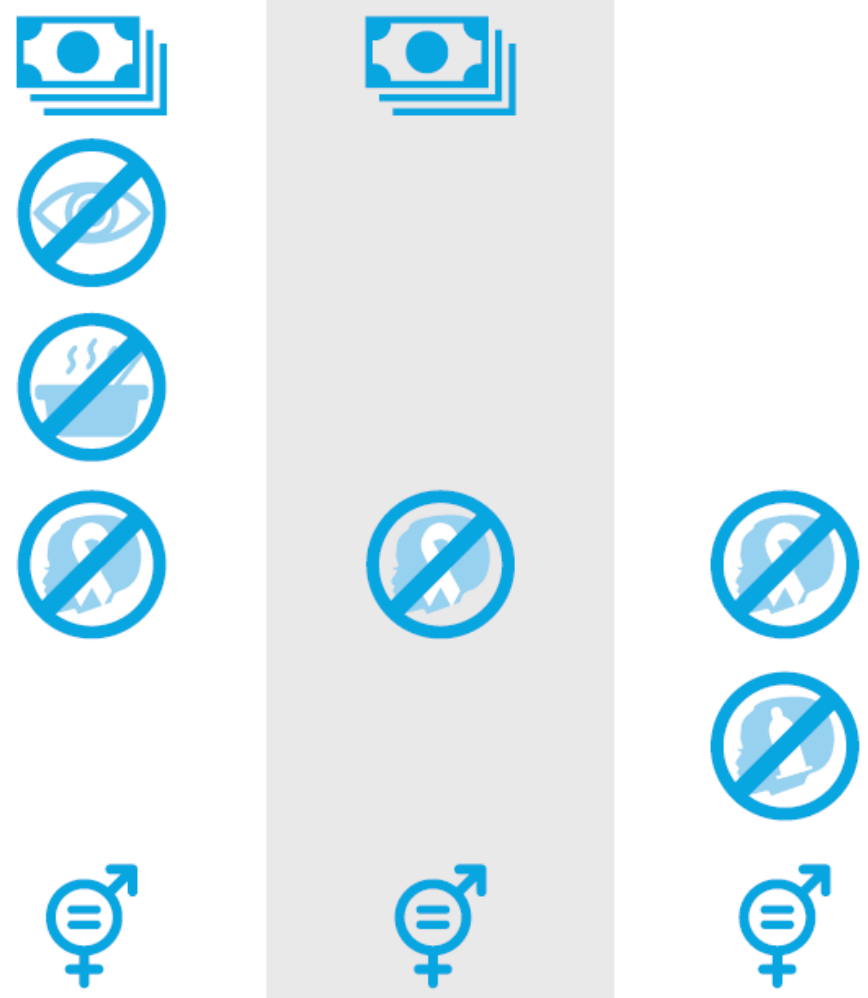
AGYW's motivations for program engagement differ by age group

- AG more receptive to knowledge, skills, building social networks, and engage in social opportunities (e.g., sport activities)

- YW keen to access skills, training, and tangible resources or options to enhance their livelihoods 


\section{Educational support \& economic interventions helped retain AGYW in programming}

I do feel it has changed the lives of other girls...it has changed them because some of them have got school fees that they can pay and... The DREAMS have also cared for them very well....

- AG, Kenya

DREAMS has changed the lives of other girls and in community. ...They have created different programs that keep young women busy like they have opened salon, barber shop, tailoring, and computer courses too that keeps them busy so that it cannot make them to idle around.... 


\section{Mentors were key for effective program implementation}

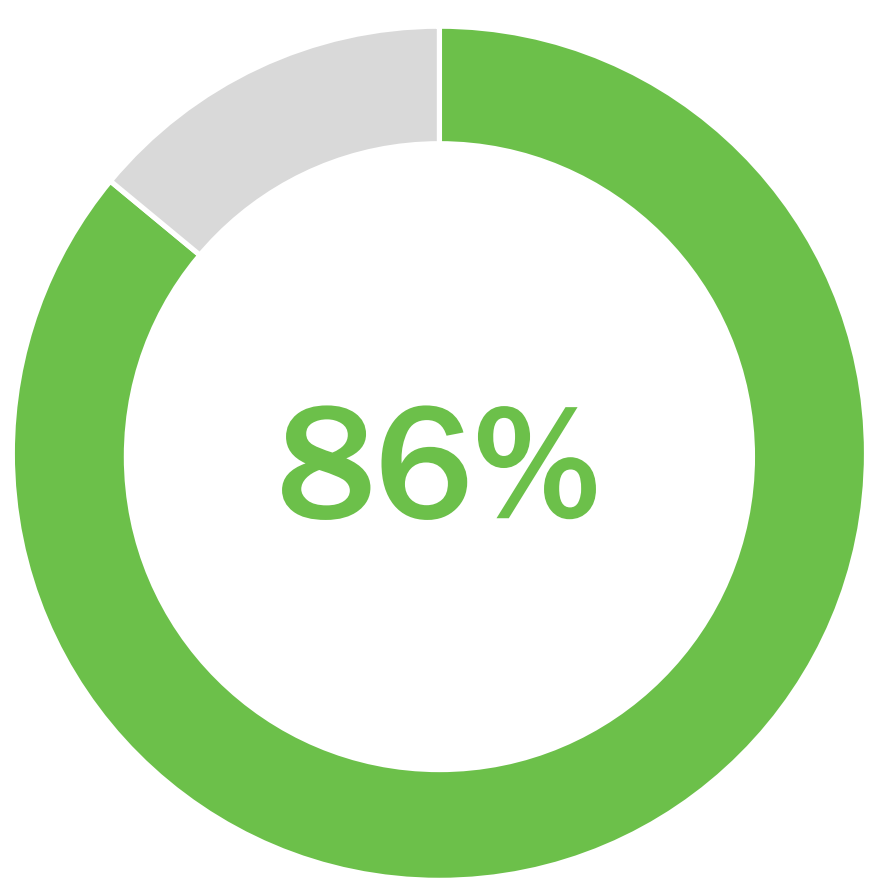

Felt comfortable seeking advice or referral from mentor
They could come and ask if there is any problem that they have. They are free to come so I feel like there is that relationship between me and the AGYWs because I am very open to every AGYW I have in my safe space. So I like it. It is like my family has grown bigger now.

\section{-Mentor, Zambia}




\section{Mentor challenges and support needed to address them}

\section{Challenges experienced}

Doubts about mentors' ability to teach/lead sessions

Workload \& material support

Parents/partner hesitancy

\section{Support needed}

Desire for additional training and workshops to reinforce/practice skills (e.g., GBV, PrEP, HIV prevention, skillful parenting)

Salary or increased monetary support (e.g., increased stipend, airtime and transportation)

Engaging local leadership for program buy-in; Components for parents and partners

...I wish if there were programs that we can engage these male sexual partners...because we teach these girls, practically they learn...but when they go back home it is different... 


\section{Many DREAMS implementing partners organically incorporated men}

...we mobilize men to receive HTC...after that, they are given information on VMMC. But we have encouraged [our CBOs] to engage men further...[for example] we trained some men as male peers in Stepping Stones, to be able to do behavior change among men.

-Implementing partner, Mukono, Uganda 


\section{Program implementers need support too}

- Tools to map AGYW in program community, and assess community resources that AGYW have access to

- Tools to strengthen skills/capacities of program mentors

- Training and partnerships to strengthen non-health components of the program

- Identify male partners of AGYW

- Use of program data to assess program effects

- Time to establish effective coordination across the multiple implementing partners and program components

- Periodic opportunities for connecting and learning from other DREAMS implementing teams 


\section{Why is addressing gender dynamics/norms central to HIV prevention?}




\section{HIV risk, relationship power \& violence}

Having relationship power strongly associated with:

$\checkmark$ Less sexual/physical violence

$\checkmark$ More condom use at last sex

$\checkmark$ More knowledge of partner's HIV status
Sexual violence experience in the last 12 months

$1.9 \%$ From partners $(n=597)$

$21 \%$ From non-intimate

partners $(n=1,778)$

\section{AGYW who experienced sexual violence were $2 x$ as likely to report an STI symptom, and anxiety and depression}

Study sites: Kenya and Zambia 


\section{Levels of empowerment can differ across AGYW age groups}
-15-17 years $\square 18-20$ years $\square 21-24$ years $(n=1,101)$

My partner has more say than I do about important decisions that affect us*

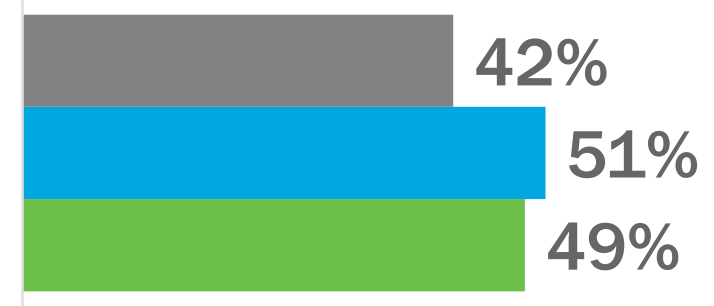

If my partner wants to have sex, he would expect me to agree*

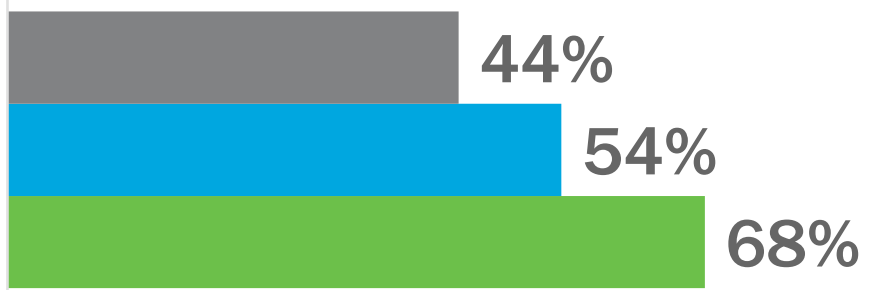

When partner and I disagree, he gets his way most of the time*

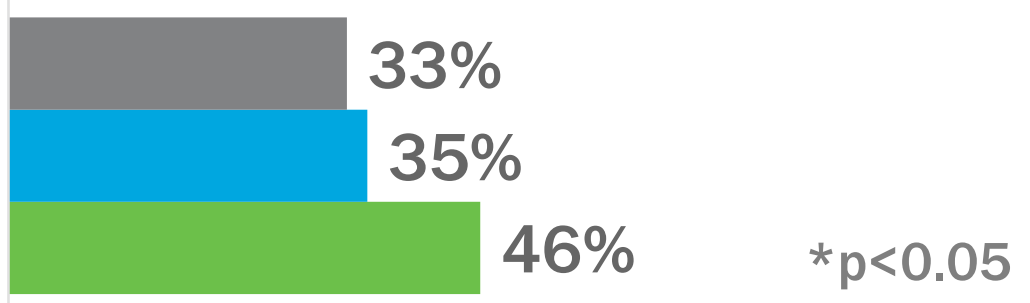

\section{Study site: Kenya}




\section{Financial autonomy can support empowerment, but only for some}

- Financial independence can afford power to reject unwanted or violent relationships

- Women's agency greater in nonmarital vs. marital relationships

- Despite more support for joint household decision-making, married women's agency still heavily influenced by cultural/ religious norms of male dominance

When you use his money, you would feel guilt and fail to refuse when he asks for sex.

-20-year-old single student 


\section{Men think about their relationships in transactional terms}

- Men see money and gifts as the only way of establishing and maintaining relationships with women

- Men see most young women as active agents in pursuing transactional sex and mainly seeking material goods

- Many men intentionally seek young women because they are more compliant (i.e., power dynamics)

A man without money get a wife or sexual partner? It doesn't exist

in our community. -Man from Uganda

The young women listen and cooperate all the time, yet older women argue.

-Man from Eswatini

Study sites: Uganda \& Eswatini 
What are the facilitators and

barriers to PrEP use

among AGYW? 


\section{PrEP provision requires}

\section{multi-level considerations}

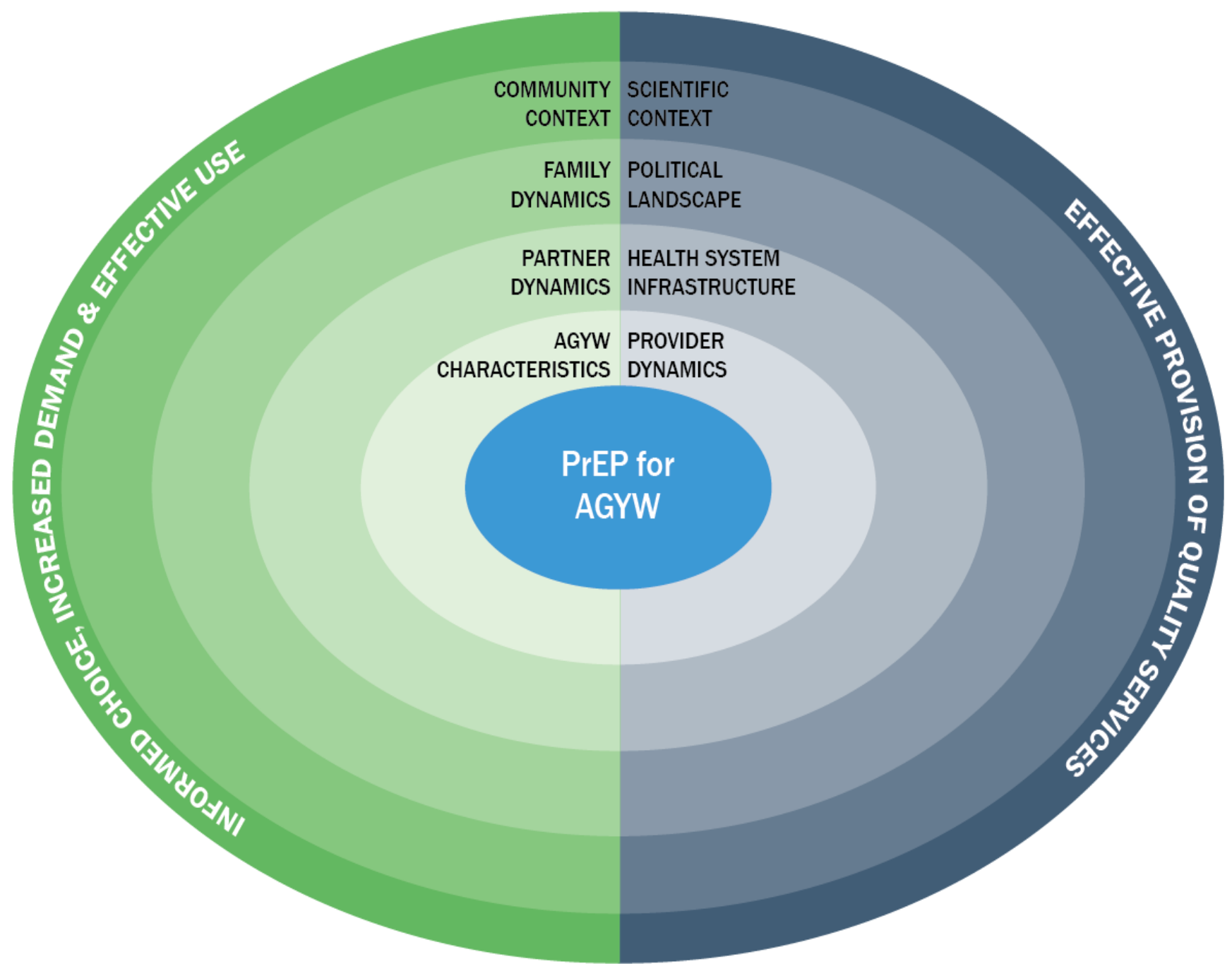

Mathur, S., N. Pilgrim, and J, Pulerwitz. 2016. PrEP introduction for adolescent girls \& young women. The Lancet HIV 3(9): e406-e408. 


\section{While nearly all AGYW were eligible for PrEP, more need access to it}

300

250

200

150

100

50

0
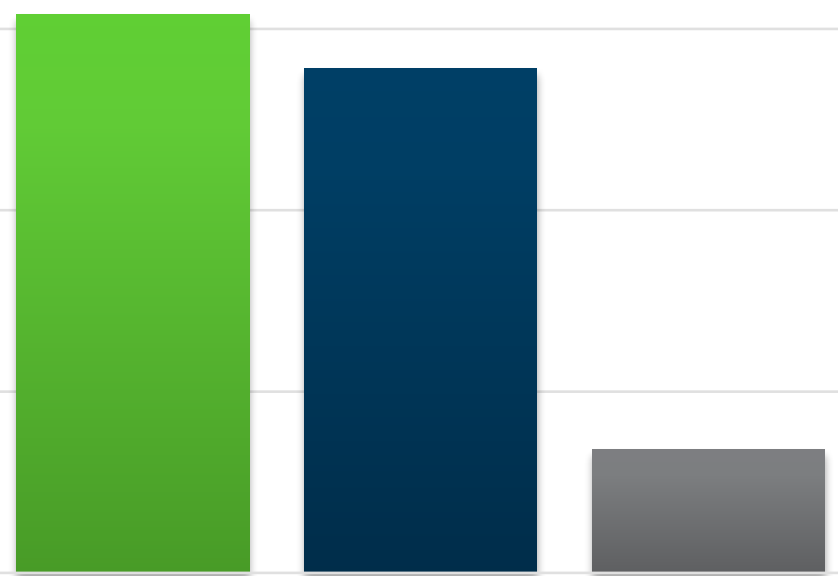

Adolescent Girls
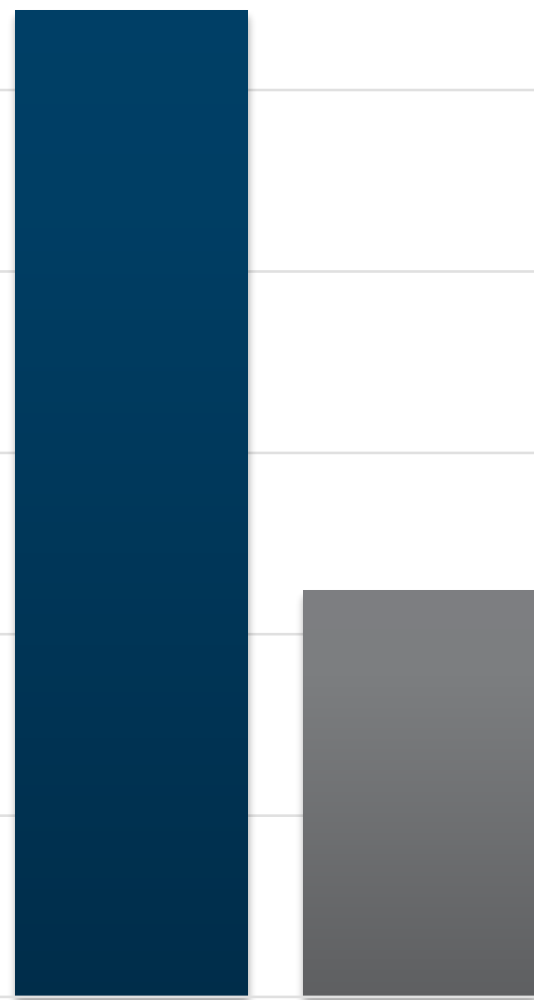

Young Women

Study site: Kenya

Respondents $\quad$ PrEP Eligible $\quad$ PrEP Consultations 


\section{Barrier to use: HIV-related stigma}

When the peers of my age see a person taking PrEP, they will think that the person has AIDS, or they are very unfaithful hanging out with many partners. They will speak many things and I will be considered as a bad person in the community, a misbehaving person.

$-\mathrm{YW}$, Tanzania

The bad thing about PrEP, it is embarrassing to swallow when you are among people who do not know that it exists because the majority know that the tablets are for people who have the [HIV] virus.

-YW, PrEP user (12 mo), Uganda

Jani, N., S. Mathur, C. Kahabuka, N. Makyao, N. Pilgrim. 2021. Relationship dynamics and anticipated stigma: Key considerations for PrEP use among Tanzanian adolescent girls and young women and male partners. PLoS ONE 16(2): e0246717.

https://doi.org/10.1371/journal.pone.0246717

Mathur, S, G Mirembe, J. Nanyondo, W. Nansalire, D. Kibirige, J. Matheka, B. Mwesigwa, A. Tindikahwa, F. Kiweewa, M. Millard, E. Akom, H. Kibuuka. 2020. "Side effects, life transitions, and disclosure: reasons for oral pre-exposure prophylaxis (PrEP) discontinuation among young women engaged in sex work in Uganda (PEC0602)." Poster presented at AIDS 2020, San Francisco, CA, USA, 6-10 July. 


\section{Barrier to use: Relationship conflict}

- Covert PrEP use by AGYW could seed mistrust within the relationship

Our relationship will be affected if he is not informed, but if I briefly explain it to him, he will understand I am using PrEP so as to protect myself from HIV infections...if he understands me properly, he can decide to accompany me and begin to take PrEP as well. But if I don't tell him and he finds them on his own, that is where the problem steps in.

-YW, Tanzania ...he [partner] came across those drugs, and he got out of control...when he found the drugs he became disturbed, furious, threw them, asked me whether a I am a commercial sex worker, whether am infected, if I had infected him. I told him the drugs are not for HIV, fearing to explain further, he would discover what I used to do.... he saw them and became furious. He poured them. He beat me to tell him the truth.... He beat me and we seriously fought....

-YW, PrEP user (8mo), Uganda 


\section{Provider perspectives on AGYW's access to PrEP}

Factors associated with providers' willingness to prescribe PrEP $(n=316)$

\begin{tabular}{|lc|}
\hline & $\begin{array}{c}\text { Adj. IRR } \\
(\mathbf{9 5 \%} \text { Cl) }\end{array}$ \\
\hline $\begin{array}{l}\text { Negative attitudes } \\
\text { toward AGYW } \\
\text { sexuality }\end{array}$ & $\begin{array}{c}0.81 \\
(0.66-0.99)^{*}\end{array}$ \\
$\begin{array}{l}\text { Behavioral } \\
\text { Disinhibition scale }\end{array}$ & $\begin{array}{c}0.89 \\
(0.79-0.99)^{*}\end{array}$ \\
\hline
\end{tabular}

\begin{tabular}{|lc|}
\hline & $\begin{array}{c}\text { Adj. IRR } \\
(95 \% \text { CI) }\end{array}$ \\
\hline $\begin{array}{l}\text { Sufficiently trained } \\
\text { to provide HIV } \\
\text { services }\end{array}$ & 1.13 \\
$\begin{array}{l}\text { Patient-centered } \\
\text { care }\end{array}$ & $1.02-1.24)^{*}$ \\
\hline
\end{tabular}

${ }^{1}$ Adjusted for provider demographics, prior PrEP knowledge, other facility factors (e.g., stockouts) ${ }^{+} p<0.10 ; * p<0.05$ 


\section{Facilitators of PrEP use among}

young women

- Perceived efficacy of PrEP for HIV risk reduction

- Perceived agency over own HIV risk

- Social support from peers and parents

- Ready-access to PrEP and supportive counseling

- Access to health care services for personal well-being 


\section{Considerations for MPTs/
biomedical technologies}
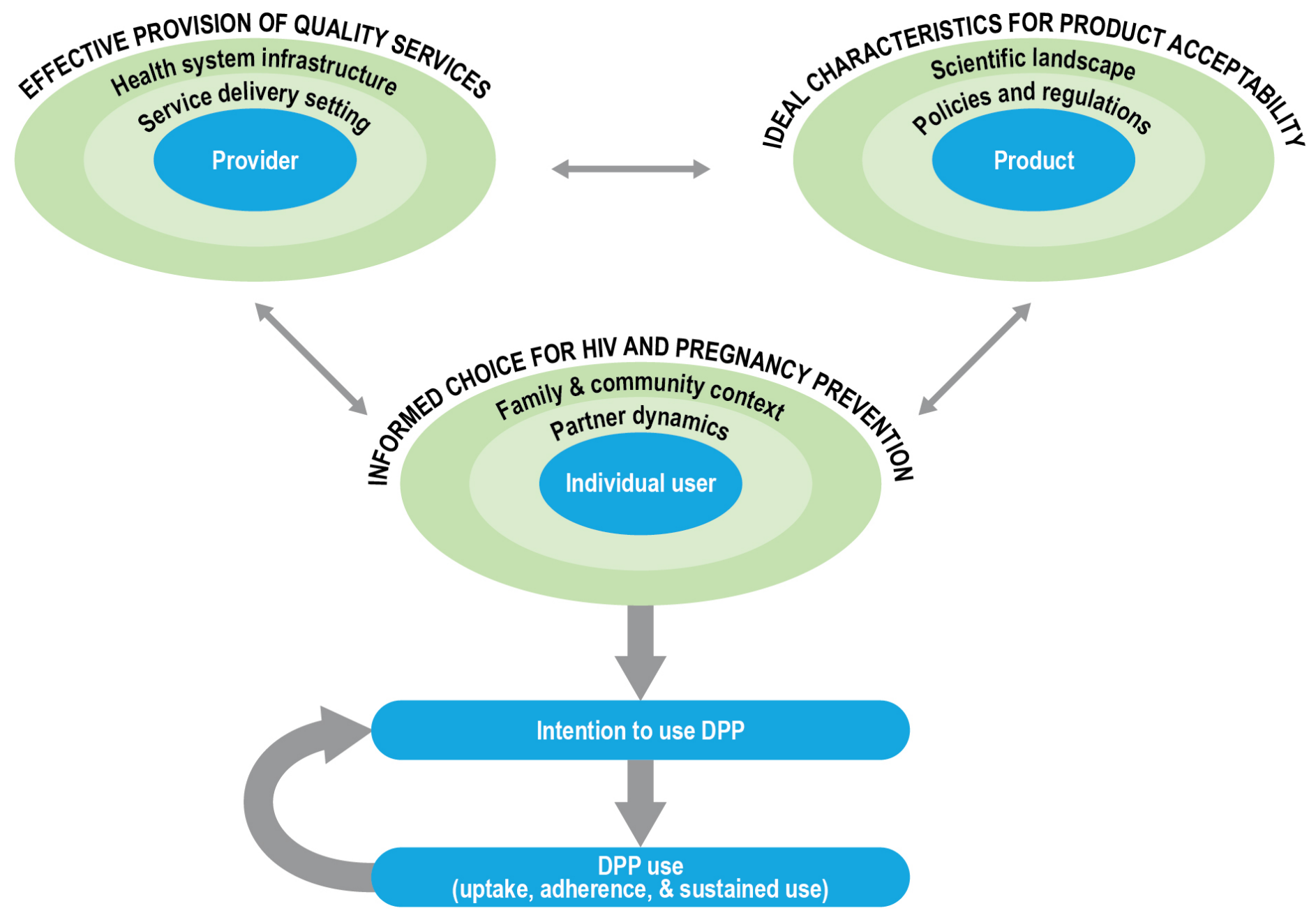
Wrap Up 


\section{Key takeaways}

Layering health and non-health interventions worked in many cases.

The "ideal" combinations of activities differed by age group and context.

Mentored safe spaces provided a unique and effective platform.

Addressing gender norms/partner dynamics and engaging men is critical.

Successful biomedical product introduction requires nuanced understandings.

Implementing partners needed to work in new ways to implement DREAMS.

Continuous application of research key for course-correction, program refinement. 


\section{Some remaining evidence gaps}

Adapting the package for different contexts/geographies. Unpack what elements of layering worked well/not well, what to emphasize, and what it costs.

Tackling long-standing inequitable gender and social norms. Critical examination of the design and intensity of programs.

Sustaining program effects. Rigorous assessments to ensure that investments are achieving the desired health/development outcomes.

Bridging the evidence to use gap. Support global and country stakeholders to interpret available evidence and align programs and policies.

Developing prevention products that people want to use. Investigate product, provider, and end-user characteristics to inform development and introduction. 


\section{Acknowledgements}

- $\quad$ Population Council: Sanyukta Mathur, Ann Gottert, Julie Pulerwitz, Miriam Temin, Jerry Okal, Maurice Musheke, Nanlesta Pilgrim, Nrupa Jani, Craig J. Heck, Sangram K. Patel, Bidhubhushan Mahapatra, Monika Walia, Louis Apicella, Mike Mbizvo, James Matheka, Drosin Mulenga, Lyson Tethani, John Mark Wiginton, Cristian Valenzuela, Pamela Keilig, Raman Mishra

- Kenya \& Zambia: Collaboration with DREAMS implementing partners (PATH/Aphia Plus, PACT) \& Iocal USAID and PEPFAR DREAMS teams

- Malawi: Local implementing partner-COM, Effie Chipeta, Victor Mwapasa, Wanangwa Chimwaza \& Collaboration with USAID/Malawi and DREAMS implementing partners

- Tanzania: Local implementing partner-CSK (Catherine Kahabuka), Neema Makyao (NACP, Tanzania) \& collaboration with NACP/MOH and local USAID and PEPFAR DREAMS teams

- South Africa: Local research partner-Epicentre: Cherie Cawood, David Khanyile \& collaboration with: South African DOH, SANAC, eThekwini Municipality, PEPFAR-South Africa, DREAMS implementing partners

- Eswatini: Local research partner \& investigators-Institute for Health Measurement (IHM): Patrick Shabangu, Bhekumusa Lukhele, Kelvin Sikwibele, Muhle Dlamini (SNAP), Muziwethu Nkhambule (NERCHA); \& collaboration with Ministry of Health, NERCHA, SNAP, PEPFAR-Eswatini, DREAMS implementing partners Uganda: Local research partner-Makerere University, Child Health and Development Centre (CHDC): Godfrey Siu, Anne Katahoire, \& Collaboration with: Makerere University Walter Reed Project, Kampala, Uganda, U.S. Army Medical Research Directorate-Africa, Kampala, Uganda U.S. Military HIV Research Program, Walter Reed Army Institute of Research, Henry M. Jackson Foundation for the Advancement of Military Medicine, Ministry of Health, District local government, PEPFAR-Uganda, DREAMS implementing partners

Funding support from the Bill \& Melinda Gates Foundation and Project SOAR/PEFAR \& USAID (Malawi) 


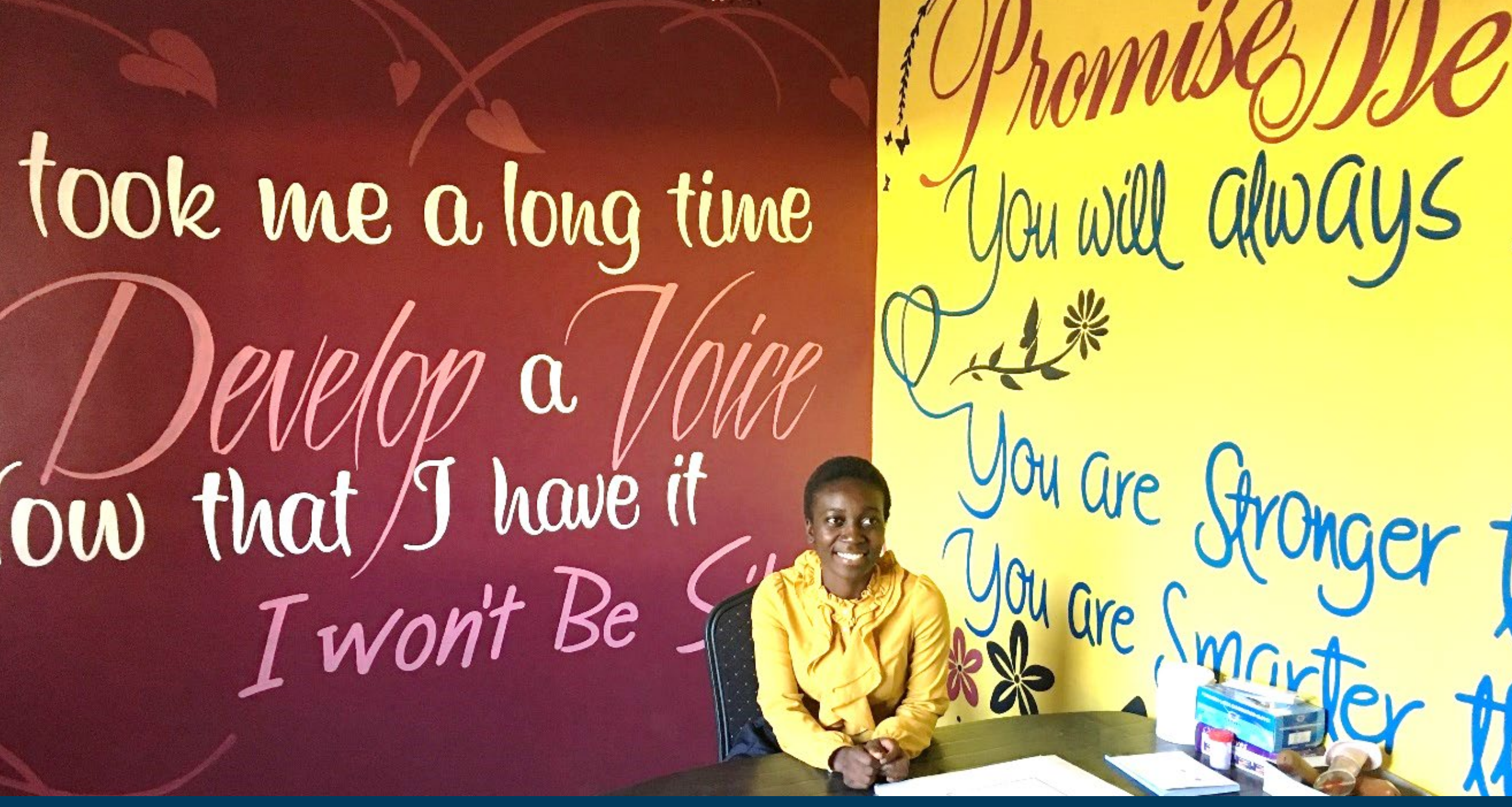

Learnings from the DREAMS Partnership

For more information, please contact:

Sanyukta Mathur

smathur@popcouncil.org

To find our publications: knowledgecommons.popcouncil.org/series_dreams 


\section{POPULATION}

COUNCIL

Ideas. Evidence. Impact.

(C) 2021 The Population Council. All rights reserved.

Use of these materials is permitted only for noncommercial purposes. The following full source citation must be included:

Pulerwitz, Julie, Ann Gottert, Jerry Okal, and Sanyukta Mathur. 2021. "Reducing HIV risk for adolescent girls and young women \& their male partners: Learnings from the DREAMS Partnership," presented to Bill \& Melinda Gates Foundation, 9 June.

This presentation may contain materials owned by others. User is responsible for obtaining permissions for use from third parties as needed. 